\title{
Correction to: What to Do and What Not to Do in the Management of Opioid-Induced Constipation: A Choosing Wisely Report
}

\author{
Domenico Alvaro - Augusto Tommaso Caraceni · Flaminia Coluzzi (D) • \\ Walter Gianni · Fabio Lugoboni · Franco Marinangeli • \\ Giuseppe Massazza • Carmine Pinto · Giustino Varrassi
}

Published online: October 20, 2020

(C) The Author(s) 2020

\section{Correction to: Pain Ther https://doi.org/10.1007/s40122-$$
\text { 020-00195-Z }
$$

One of the author names was incorrectly published in the original article as Franco Mariangeli. The correct name should be Franco Marinangeli.

The original article has been corrected.

The original article can be found online at https://doi. org/10.1007/s40122-020-00195-z.

\section{Alvaro}

Department of Translational and Precision

Medicine, Gastroenterology Division, Sapienza

University of Rome, Rome, RM, Italy

\section{A. T. Caraceni}

Palliative Care, Pain Therapy, and Rehabilitation

Unit, Fondazione IRCCS Istituto Nazionale dei

Tumori, Milan, MI, Italy

F. Coluzzi $(\bowtie)$

Department of Medical and Surgical Sciences and Biotechnologies, Sapienza University of Rome, Latina, LT, Italy

e-mail: flaminia.coluzzi@uniroma1.it

F. Coluzzi

Anesthesiology, Intensive Care, and Pain Medicine Unit, Sant'Andrea University Hospital, Rome, RM, Italy

W. Gianni

Department of Internal Medicine and Geriatry, University Hospital Policlinico Umberto I, Rome, RM, Italy

\section{OPEN ACCESS}

This article is licensed under a Creative Commons Attribution-NonCommercial 4.0 International License, which permits any noncommercial use, sharing, adaptation, distribution and reproduction in any medium or format, as long as you give appropriate credit to the original author(s) and the source, provide a link to the Creative Commons licence, and indicate if changes were made. The images or other third party material in this article are

F. Lugoboni

Department of Medicine, Addiction Unit, University Hospital of Verona, Verona, VR, Italy

\section{F. Marinangeli}

Department of Anesthesiology, Pain Medicine, and Palliative care, University of L'Aquila, L'Aquila, AQ, Italy

\section{G. Massazza}

Division of Physical Medicine and Rehabilitation, Department of Surgical Sciences, University of Turin and "Città della Salute e della Scienza" University Hospital, Turin, TO, Italy

C. Pinto

Medical Oncology Unit, Clinical Cancer Center, Azienda USL-IRCCS di Reggio Emilia, Reggio Emilia, RE, Italy

G. Varrassi

Paolo Procacci Foundation, Rome, RM, Italy 
included in the article's Creative Commons licence, unless indicated otherwise in a credit line to the material. If material is not included in the article's Creative Commons licence and your intended use is not permitted by statutory regulation or exceeds the permitted use, you will need to obtain permission directly from the copyright holder. To view a copy of this licence, visit http://creativecommons.org/licenses/by$\mathrm{nc} / 4.0 /$. 